Marquette University

\title{
e-Publications@Marquette
}

Management Faculty Research and

Publications

Management, Department of

$9-2010$

\section{The Impact of Passing the Professional in Human Resources Exam on Early Career Success for Undergraduates Entering the Human Resource Field}

\author{
Scott W. Lester \\ University of Wisconsin - Eau Claire \\ Jennifer Mencl \\ University of Minnesota - Duluth \\ Cheryl Maranto \\ Marquette University, cheryl.maranto@marquette.edu \\ Kristina A. Bourne \\ University of Wisconsin - Eau Claire \\ Timothy Keaveny \\ Marquette University, timothy.keaveny@marquette.edu
}

Follow this and additional works at: https://epublications.marquette.edu/mgmt_fac

Part of the Business Commons

\section{Recommended Citation}

Lester, Scott W.; Mencl, Jennifer; Maranto, Cheryl; Bourne, Kristina A.; and Keaveny, Timothy, "The Impact of Passing the Professional in Human Resources Exam on Early Career Success for Undergraduates Entering the Human Resource Field" (2010). Management Faculty Research and Publications. 42.

https://epublications.marquette.edu/mgmt_fac/42 
Marquette University

e-Publications@Marquette

\section{Management Faculty Research and Publications/College of Business Administration}

This paper is NOT THE PUBLISHED VERSION; but the author's final, peer-reviewed manuscript. The published version may be accessed by following the link in the citation below.

International Journal of Selection and Assessment, Vol. 18, No. 3 (September 2010): 282-290. DOI. This article is (C) Wiley and permission has been granted for this version to appear in e-

Publications@Marquette. Wiley does not grant permission for this article to be further copied/distributed or hosted elsewhere without the express permission from Wiley.

\section{The Impact of Passing the Professional in Human Resources Exam on Early Career Success for Undergraduates Entering the Human Resource Field}

Scott W. Lester

Management and Marketing Department, University of Wisconsin - Eau Claire, Eau Claire, WI Jennifer Mencl

University of Minnesota Duluth, Duluth, MN

Cheryl Maranto

Marquette University, Milwaukee, WI

Kristina A. Bourne

University of Wisconsin - Eau Claire, Eau Claire, WI

Timothy Keaveny

Marquette University, Milwaukee, WI 


\section{Abstract}

This study investigates the impact of passing the Professional in Human Resources (PHR) certification exam on the early career success of recent college graduates. Data were gathered from alumni of three Midwestern universities who earned an undergraduate degree in business administration (i.e., BBA) with a major in human resources. The survey was designed to measure early career success indicators including finding a job in the HR field, starting salary, and number of promotions. Results reveal that the probability of one's first job after graduation being in human resources was significantly greater for those who had passed the PHR exam compared with those who did not pass or did not take the exam. Passing the PHR exam was not associated with significant differences in starting salary or early career promotions. Implications, study strengths and limitations, and suggestions for future research are discussed.

\section{Introduction}

Today's companies face increased competition and an economy in recession. In this challenging environment, it is imperative that firms can be confident that their new hires have the competencies to be productive contributors. As a result, there is a need to standardize the definition of professional competency and to identify those who possess the knowledge, skills, and abilities required for navigating current and future business arenas (Hansen, 2006; Wiley, 1999). This need has led to the proliferation of professional and technical certification programs, which demonstrate an individual's mastery of a specified body of knowledge and his or her qualifications to successfully and competently perform in his or her job function (Miracle, 2007; Wiley, 1999).

Some certifications are mandated by federal or state regulations, requiring individuals who pursue occupations such as teacher, public accountant, lawyer, or pharmacist to pass the relevant standardized test and maintain the certification to work in the occupation. In contrast, voluntary certifications provide individuals with a choice to take exams designed for particular professions, including jobs in information technology, financial management, and internal auditing (Hansen, 2006). The benefit of pursuing voluntary certification(s) for any occupation is that individuals can set themselves apart from those without this type of qualification (Hunsinger \& Smith, 2008).

Because of this distinction, understanding the impact of voluntary certifications can contribute to research addressing the qualifications that new job entrants need to be successful early in their careers (Eby, Butts, \& Lockwood, 2003; Gattiker \& Larwood, 1988; Waldman \& Korbar, 2004). As the nature of psychological contracts has changed (i.e., employees no longer have assurances of job security) and career paths have become 'boundaryless' (Arthur, Khapova, \& Wilderom, 2005; Sturges, Conway, Guest, \& Liefooghe, 2005), it is important to understand how unique qualifications will impact the career success of today's college graduates. Recently, it was estimated that approximately 1,600 voluntary certifications are available across a wide variety of fields (Hansen, 2006).

Human resource management (HRM) is one professional field that is following this trend toward increased use of voluntary certification (see, e.g., Cherrington \& Leonard, 1993; Glister, 2000; Losey, 1993; McFarland, 2000; Meisinger, 2004; Sunoo, 1999; Tyler, 1997; Wiley 1992a, 1992b, 1999). While there is anecdotal evidence of the positive impact of passing the PHR exam on early career success, little empirical research has examined these claims. The overarching purpose of this study is to fill this gap in the HRM literature.

The Society for Human Resource Management (SHRM), the largest professional organization for human resource (HR) professionals world-wide, promotes a variety of voluntary certifications offered through the HR Certification Institute. This certifying organization, which is accredited by the National Commission for Certifying 
Agencies, now has four certifications: (1) Professional in Human Resources (PHR), (2) Senior Professional in Human Resources (SPHR), (3) Global Professional in Human Resources (GPHR), and (4) PHR with state certification in California and SPHR with state certification in California (PHR-CA and SPHR-CA). Each certification, and resulting designation, signifies the mastery of a particular area of the HR body of knowledge. Specifically, the PHR is intended for those whose focus is program implementation as well as technical and operational tasks, the SPHR is intended for those with a focus on program design and strategic roles, while the GPHR is intended for those who function in the international business environment. The California designation was designed specifically for HR professionals working in that state.

The PHR certification exam is currently available to students and recent graduates of bachelor's and/or graduate degree programs. Each student who passes the test must complete 2 years of exempt-level HR experience within 5 years after passing the test to actually obtain the certification. Although students and recent graduates passing the test are not technically certified as a PHR, having the qualification that they have reached a standardized level of proficiency in HRM knowledge is one unique distinction that can separate HR graduates from others seeking HR-related jobs (HR Certification Institute, 2008a). This ability to differentiate oneself is extremely important in a field where new entrants to the profession find it difficult to obtain employment without experience and yet are unable to gain experience if employers are not willing to hire them at such an early stage in their career.

This investigation is timely due to a recent decision by the HR Certification Institute to change the PHR eligibility requirements. Beginning in the spring of 2011, students and recent graduates will no longer be able to take the PHR exam without already possessing the 2 years of exempt-level work experience. This decision has sparked a debate about whether an alternative job knowledge test should be created to allow new entrants to the HR profession (who lack the exempt-level experience) an opportunity to distinguish themselves. Results of the current study will inform this debate by addressing whether there is empirical evidence to support the contention that voluntary certification facilitates entry into the HR profession and leads to other objective measures of early career successes.

\section{PHR certification and career success}

Career success is the accumulation of objective and subjective work-related outcomes and achievements attained at any point during a person's work experiences (Arthur et al., 2005; Waldman \& Korbar, 2004). Objective career success refers to the external, tangible rewards one receives during his or her career - that is, extrinsic rewards received from one's career (Arthur et al., 2005; Heslin, 2005). Salary and promotions are common examples of objective career success. Subjective career success is an individual's internal evaluation of his or her career - that is, intrinsic rewards received from one's work experiences (Arthur et al., 2005). Subjective career success is commonly measured as job satisfaction or career satisfaction (Heslin, 2005).

To our knowledge, very few empirical studies during the past two decades have examined the importance of the PHR certification as a facilitator of career success. This dearth of research on the topic is troubling. The two published studies on this topic are quite different in nature and thus difficult to directly compare. Nevertheless, it is important to briefly review their findings to explore the possible role of PHR certification on various career success measures.

First, in the early 1990s, Wiley (1992b) surveyed HR professionals who had received either PHR or SPHR certification to pose several important yet unanswered questions about the voluntary certification. Her results revealed that respondents sought certification for professional accomplishment, personal satisfaction, demonstration of HR knowledge, and career advancement. In fact, one-third of the sample reported one to three promotions after earning HR certification. Respondents also reported salaries that were competitive with 
national averages. Wiley's findings suggest that passing the PHR could contribute to the career success for recent college graduates through job promotions and competitive salaries. However, this generalization may not be accurate considering that the majority of her sample (76\%) already had at least 5 years of exempt experience. The study also lacked a comparison group of HR professionals who had not received a PHR or SPHR certification, so there is no evidence of whether the certification actually had an impact on career advancement.

More recently, Aguinis, Michaelis, and Jones (2005) investigated the relationship between HR certification and HR career opportunities by analyzing HR job announcements on http://monster.com, http://hotjobs.yahoo.com, http://careerbuilder.com, and http://shrm.org to determine if employers required potential HR recruits to hold an HR certification. The study examined whether employers preferred applicants who held an HR certification over those who did not and whether the job vacancies stating an HR-certification preference were associated with higher salary ranges. After analyzing 1,873 HR-specific job announcements from a 1-week period, the authors found that only $4.2 \%$ of the job announcements required or preferred HR certification. Additionally, the jobs requiring HR certification were not associated with higher salary ranges.

These findings suggest that most organizations do not require or prefer HR certification among applicants nor do they reward PHR certification with higher salaries. These results are consistent with research conducted by the HR Certification Institute (2008b) that indicates less than $10 \%$ of organizations require HR certification for exempt-level positions. Although these findings together suggest that recent college graduates may not benefit from HR certification, the HR Certification Institute survey also revealed that about one-half of the participating certified HR professionals reported that they received recognition from their organization and approximately one-third received higher pay because of their certification (HR Certification Institute, 2008b).

These findings, while interesting, either do not directly focus on our population of interest or do not directly address the link between passing the PHR and objective early career success. First, the HR Certification Institute sample consisted of those who had fulfilled the exempt-level experience requirement to be fully certified, which means their outcomes may in part have been driven by their in-house performance rather than merely passing the PHR exam. The Aguinis et al. (2005) study is also incapable of giving us a true understanding of the relationship between passing the PHR and salary because it examines archival data to calculate the percentage of positions that require or prefer this designation from their hires. Although a low percentage require certification, the study does not answer the question of whether a job candidate having passed the PHR exam could expect a higher starting salary offer (within the established range) than a counterpart who did not earn this external validation of his/her knowledge.

More empirical evidence is clearly required if we are to clarify the impact that passing the PHR certification exam has on early career success and to understand its real value as a job-specific qualification, especially for recent HR graduates. Consequently, we surveyed alumni who earned an undergraduate degree in business administration (i.e., BBA) with a major in HR to focus on recent college graduates who do not have as much work experience compared with the HR veterans studied previously (HR Certification Institute, 2008b; Wiley, 1992b).

Our sample was intentionally comprised of individuals who passed the PHR as well as those who did not take or did not pass the PHR, which allows us to draw more applicable inferences regarding the likely impact of passing the PHR on early career outcomes as well as the possible effects of the upcoming change in the PHR eligibility requirements on undergraduate HR majors. In the following paragraphs we draw on human capital theory, the contest mobility norm, signaling theory, and evidence regarding the predictive validity of job knowledge tests to establish the theoretical framework for our proposed relationships between passing the PHR exam and early 
career success. We focus on the objective career success outcomes of getting a job in the HR field after graduation, starting salary, and expedited career progression (as measured by number of promotions).

\subsection{Early career success: Employment in the HR field}

According to human capital theory, individuals consciously choose to invest time, effort, and money in personal development based upon an assessment of the potential costs and benefits of that investment (Wayne, Liden, Kraimer, \& Graf, 1999). Thus, by examining the cost (time, effort, and money) and potential rewards (early career success) of passing the PHR exam, individuals will make a rational decision to take the exam or not. Taking the PHR exam can be viewed as an investment in an individual's human capital, with the expectation that doing so will increase earnings or other career outcomes.

Passing the PHR certification exam is also expected to provide a 'signal' to potential employers. Signaling theory (Spence, 1973) suggests that taking and passing the exam provides an important signal to potential employers regarding that individual's competence, drive, focus, and career interest, even if passing the PHR exam is not a professional requirement. Supporting this notion that employers respond favorably to competence 'signals' from employees, data from the information technology field shows a positive relationship between certification and compensation (Hunsinger \& Smith, 2008).

Although empirical research on the impact of certification in the HR field is limited, and to our knowledge there has been no prior examination of the impact of passing the PHR (before fulfilling the exempt-level experience requirement), passing a certification exam is likely to give recruiters greater confidence in the applicant's command of the standard body of knowledge in a profession. This inference is reasonable given evidence concerning the predictive validity of job knowledge tests in general. A meta-analytic study of 502 investigations concluded that job knowledge tests have high validity in predicting job performance (Dye, Reck, \& McDaniel, 1993).

Drawing on the research described above, we expect that passing the PHR exam increases the probability that recent alumni of undergraduate programs majoring in HR will secure a job in the HRM field.

H1: Passing the PHR certification exam is positively associated with obtaining a job in the HRM field after graduation.

\subsection{Early career success: Starting salary}

We expect that passing the PHR exam and getting a job in the HR field will lead to additional career success. This is supported by the contest-mobility norm that suggests 'the organization rewards individuals who possess higher levels of human capital' (Wayne et al., 1999: p. 580). The contest-mobility norm assumes that employees' outcomes such as salary level and promotions are a function of hard work, ability, education, and/or training (Turner, 1960) - factors closely linked to investing in human capital. We pair the contest-mobility norm with human capital theory to provide an integrated framework for understanding the relationship between passing a professional certification exam and objective career success.

Certification has been linked to increased salaries across many occupations (Weeden, 2002). Higher salaries were observed among accountants with professional certifications (Robert Half International Inc., 2005), ITcertified professionals (Hunsinger \& Smith, 2008; Roberts, 2002), and nurses (Briggs, Brown, Kesten, \& Heath, 2006). Focusing on the HR field, as discussed previously, Aguinis et al. (2005) found that job announcements requiring or preferring $\mathrm{HR}$ certification were not associated with higher salary ranges. However, approximately one-third of certified HR professionals surveyed in a separate study reported higher pay due to their certification (HR Certification Institute, 2008b). We extend research focused on salary by employing a more precise measure, asking participants to report their starting salary. While it is unlikely that an employer would depart 
from an established salary range when hiring, differential qualifications above minima would be expected to influence where within the salary range an offer is likely to be made.

Furthermore, Wiley (1992b) found that organizations extrinsically rewarded those who earned an HR certification by providing them with competitive pay. This study, however, included only participants who had HR certification. Consequently, no comparison regarding pay between those with and without certification was possible. The current investigation builds on the Wiley (1992b) study by permitting a comparison between those who have passed the PHR versus those who chose not to take the exam and those who failed the exam. Our hypothesis states:

H2: Passing the PHR certification exam is positively related to starting salary for those who obtain a job in the HRM field after graduation.

\subsection{Early career success: Expedited promotion}

Another measure often used to assess objective career success is the number of promotions that an individual receives. Signaling theory suggests that passing a certification exam would be one signal to an employer that an individual has the capacity and skills to get on the 'fast track' to advancement (Spence, 1973). Research in the IT field suggests a positive relationship between professional certifications and promotions (Tyler, 1997; Campbell, 2004). In addition, the evidence regarding the ability of job knowledge tests to predict job performance discussed above (Dye et al., 1993) suggests a positive relationship between certification and number of promotions. An employee's command of a professional body of knowledge is likely to lead to superior performance in their initial job with the company, which in turn should improve their promotional opportunities. We posit that passing the PHR exam is positively associated with promotions among recent alumni of undergraduate HR programs who are working in the HRM field.

H3: Passing the PHR certification exam is positively related to number of promotions earned by recent alumni of undergraduate HR programs employed in the HRM field.

\section{Methods}

\subsection{Procedure and participants}

Our study examines alumni of undergraduate HR programs from three different Midwestern universities representing three distinct approaches to whether the PHR certification exam should be taken at the undergraduate level. University 1 requires its undergraduate HR majors to take the PHR exam as part of its curriculum, and the required capstone course for the major is designed to prepare students for the exam. Only students who pass the PHR exam graduate as HR majors; those who decide not to take the exam or who fail the exam become general management majors. University 2 encourages its HR students to take the PHR but does not require them to take the exam. Students have the choice to participate in study groups that are not part of their regular course work before the May-June PHR testing window. University 3 does not promote the PHR exam in any way, nor does it offer a structured method to study for the exam. Our sample consists of alumni of undergraduate HR programs who passed the PHR exam, failed the PHR exam, or chose not to take the PHR exam.

A letter was sent to HR alumni of these three Midwestern universities who graduated between 1996 and 2007. The letter described the intent of the research project and asked each alumnus to provide a current email address. Two hundred and ninety-three alumni from University 1 were sent letters, as were 337 from University 2 , and 150 from University 3. The number of alumni responding with a current email address from each university was: 159,124 , and 71 , respectively. An email message containing a hyperlink to an online survey was sent to the respondents who had provided their email addresses. This procedure protected access to the survey 
and allowed for cost savings, speed of response, and ease of administration (Forrest, 2003; Burns \& Bush, 2005; McDaniel \& Gates, 2005).

Of those alumni who received the hyperlink to the online survey, 96 graduates from University 1 (60\% response rate), 73 graduates from University 2 (59\% response rate), and 61 graduates from University 3 ( $86 \%$ response rate) responded, for a total sample size of 230 . Based on demographic information reported, $79 \%$ of the total sample was female, $94 \%$ were white/non-Hispanic, $13 \%$ had earned a master's degree after receiving their bachelor's degree, and the mean undergraduate GPA was 3.21 (4.0 scale). On average, respondents graduated 5.33 years before 2008 .

\subsection{Measures}

\subsubsection{PHR exam}

The survey asked respondents two questions regarding the PHR exam. 'Did you take the PHR exam?' (yes/no); and those who responded 'yes' were then asked, 'Did you pass the PHR exam?' (yes/no). Questions also asked the date of graduation and the date the exam was taken. One hundred and eighteen alumni indicated they had passed the PHR exam, 23 alumni indicated they failed the certification exam, and 89 alumni indicated that they chose not to take the PHR exam. However, if respondents reported taking or passing the exam after the year of graduation, they were coded as not taking and not passing the PHR for purposes of analyzing their first job, to capture their status during the job search. One hundred and twenty-four alumni indicated that they took the exam before or in the same year they earned their degree, and 100 had passed the PHR exam by that time.

\subsection{2. $H R$ job}

One question asked for the title of the first job held after graduating from college. Options included benefits administrator, compensation analyst, director of human resources, director of training and development, human resource assistant, human resource generalist, recruiting coordinator, and training specialist. Participants were also given the choice to select 'other' and provide the specific title. All of the HR-specific title options and openended responses that provided evidence of an HR job (e.g., training coordinator, HR representative, staffing coordinator) were coded as ' 1 '. We also validated this by cross-checking the responses against a separate question that asked respondents to check any of the HR functions they were (are) primarily responsible for (benefits, career development, compensation, employee relations, health and safety, labor relations, recruiting, selection, and training). Seventy-two percent of the respondents reported having a first job in the HR field.

\subsubsection{Starting salary}

Respondents were asked to report the 'base salary (in thousands, excluding bonuses and stock options)' for their first job.

\subsubsection{Promotions}

Respondents were asked questions regarding their second, third, fourth, and fifth positions after graduating from college. With respect to each position, respondents were asked if the move to the position was the result of a promotion. This allowed respondents to classify job changes within and between organizations as promotions based on their discretion. These were summed to form a variable labeled 'promotions.'

\subsection{Comparison groups and control variables}

A methodological challenge of this study is the inherent difficulty of obtaining a comparison group with which to measure the impact of passing the PHR exam. Any certification that is purely voluntary is likely to be sought by individuals who differ from those who do not seek it, perhaps in motivation or career focus. Thus, test-takers may differ from nontest-takers in ways that impact the probability of obtaining a job in HR. 
One possible approach would be to compare those who took and passed the test with those who took and failed it. There are two problems with this approach. First, these two groups also differ in their job knowledge and competence - a far greater threat to a valid comparison than possible differences in motivation. Additionally, there are so few respondents in our sample who took and failed the test that there is insufficient statistical power to estimate its effect. Another approach would be to compare the effect of passing the PHR with the effect of taking the PHR (both passing and failing). Once again, the small number of respondents who reported taking and failing the exam means that the estimated impact of taking the exam is likely to be driven by the impact of passing - they cannot be separated from one another. Alternatively, we can utilize the fact that the three schools take distinct approaches to the exam, which are clearly communicated to students. One school requires it, one supports and encourages it, and one follows a laissez faire approach. If school policy systematically influences student decisions about whether and why to take the exam, we can control for differences in motivation for taking the exam by including dummy variables for the school from which they received their HR degree. Each university was coded as a dummy variable with University 1 the omitted comparison school. Inclusion of the university dummy variables controls for systematic differences in the nature of the HR program and differences in the predominant labor market in which graduates obtain employment, as well as the treatment of the PHR in the program and thus motivation for taking the PHR exam.

\subsection{Analyses}

Hypothesis 1 (whether passing the test increases the odds of obtaining a job in the HRM field) was tested with the full sample after deletion for missing values $(N=206)$ using logistic regression. Hypotheses 2 and 3 (pertaining to starting salary and promotions,) were tested with the subset of respondents who obtained their first job after graduation in the HRM field $(N=138)$ using linear regression analysis. The subset of respondents whose first job was in HR was deemed most appropriate for testing the second and third hypotheses because our interest is in career outcomes for HR majors who entered the HRM field. Additionally, it is a means of controlling for differences in average starting salaries across business fields. HRM positions usually command lower salaries than positions in other business fields such as accounting, finance, MIS, and logistics (National Association of

Colleges \& Employers, 2009). Before analysis, two cases were removed as outliers based on self-reported salaries of US\$99,900 and US\$72,000. Our judgment is that these salaries are abnormally high for entry-level HR positions for graduates of these universities. Further, inclusion of these observations skewed the distribution for the salary variable. After removing these cases, all dependent variables were normally distributed.

\section{Results}

Means, standard deviations, and correlations for the variables in this study are presented in Table 1. Descriptive statistics and correlations below the diagonal in Table 1 pertain to the full sample (used to test Hypothesis 1), and descriptive statistics and correlations above the diagonal in Table 1 pertain to those alumni whose first job after graduation was in HR (used to test Hypotheses 2 and 3). Because gender, GPA, years after graduation, and universities were correlated with one or more dependent variables at statistically significant levels, they were used as control variables in the analyses. 
Table 1. Means, standard deviations, and correlations ${ }^{a}$

\begin{tabular}{|l|l|l|l|l|l|l|l|l|l|l|l|l|l|}
\hline & $\mathbf{M}$ & $\mathbf{S D}$ & $\mathbf{1}$ & $\mathbf{2}$ & $\mathbf{3}$ & $\mathbf{4}$ & $\mathbf{5}$ & $\mathbf{6}$ & $\mathbf{7}$ & $\mathbf{8}$ & $\mathbf{9}$ & $\boldsymbol{M}$ & $\mathbf{S D}$ \\
\hline 1. Gender $^{\mathrm{b}}$ & 0.19 & 0.40 & - & $-.26^{* *}$ & -.07 & -.13 & $.25^{* *}$ & -.10 & -.01 & $.19^{*}$ & -.02 & 0.14 & 0.34 \\
\hline 2. GPA & 3.21 & 0.36 & $-.26^{* *}$ & - & .03 & $.17^{*}$ & -.07 & -.12 & $.28^{* *}$ & .09 & $.15^{*}$ & 3.22 & 0.35 \\
\hline 3.Years after graduation & 5.33 & 3.04 & -.11 & .05 & - & .12 & -.02 & -.11 & -.06 & $-.30^{* *}$ & $.24^{* *}$ & 5.50 & 3.04 \\
\hline 4. University 1 & 0.43 & 0.50 & -.08 & .13 & $.17^{*}$ & - & $-.56^{* *}$ & $-.53^{* *}$ & $.58^{* *}$ & -.10 & .07 & 0.43 & 0.50 \\
\hline 5. University 2 & 0.29 & 0.46 & $.15^{*}$ & -.06 & -.08 & $-.56^{* *}$ & - & $-.40^{* *}$ & -.12 & -.02 & -.03 & 0.29 & 0.46 \\
\hline 6. University 3 & 0.27 & 0.45 & -.06 & -.08 & -.10 & $-.54^{* *}$ & $-.40^{* *}$ & - & $-.53^{* *}$ & .13 & -.05 & 0.27 & 0.45 \\
\hline 7. Passed PHR & 0.45 & 0.50 & -.02 & $.24^{* *}$ & .01 & $.62^{* *}$ & $-.17^{*}$ & $-.51^{* *}$ & - & -.02 & .01 & 0.48 & 0.50 \\
\hline 8. Job 1 salary & $32,113.99$ & $7,113.21$ & $.15^{*}$ & .03 & $-.24^{* *}$ & -.14 & -.08 & $.24^{* *}$ & -.12 & - & -.06 & $31,542.14$ & $5,840.64$ \\
\hline 9. Promotions & 0.58 & 0.86 & -.02 & .10 & $.27^{* *}$ & .04 & -.03 & -.01 & .00 & -.09 & - & 0.65 & 0.90 \\
\hline 10. Job 1 in HR $^{b}$ & 0.73 & 0.44 & $-.24^{*}$ & .06 & .10 & .00 & .00 & -.00 & .10 & -.13 & .13 & 1.00 & 0.00 \\
\hline
\end{tabular}

Notes. ${ }^{a}$ Descriptive statistics and correlations below the diagonal are for the full sample ( $N=190$ with listwise deletion of missing values). Descriptive statistics and correlations above the diagonal are for the alumni whose first job after graduation was in HR ( $N=139$ with listwise deletion of missing values).

${ }^{\mathrm{b}}$ Dichotomous variables, Gender: 0=Female, 1=Male, Passed PHR: 0=Did Not Take/Did Not Pass PHR, 1=Passed PHR, Job 1 in HR: 0=No, $1=$ Yes. ${ }^{*} p<.05 ;{ }^{* *} p<.01$. 
Hypothesis 1 proposed that those passing the PHR certification exam would be more likely to obtain a job in the HRM field upon graduation. The control variables were entered in the first block of the logistic regression, and passing the PHR was entered in the second block. Results demonstrated a statistically significant $\chi^{2}$ change for the second block, $\chi^{2}(1, N=190)=5.45, p<.05$, showing the percentage of individuals employed in an HR job varied by whether respondents had passed the PHR or not. Those who passed the PHR were more than twice as likely to obtain an HR job than those who did not take or did not pass the exam, $\operatorname{Exp}(B)=2.84$ (see Table 2). This finding strongly supports Hypothesis 1.

Table 2. Logistic regression results - determinants of first job in HR after graduation

\begin{tabular}{|l|l|l|}
\hline Variable & B (SE) & Exp(B) \\
\hline Block 1 & & \\
\hline Gender & $-1.29^{* *}$ & 0.27 \\
\hline & $(.38)$ & \\
\hline GPA & 0.14 & 1.15 \\
\hline Years after graduation & $(.46)$ & \\
\hline & 0.03 & 1.03 \\
\hline University 2 & $(.05)$ & \\
\hline & 0.20 & 1.22 \\
\hline University 3 & $(.39)$ & \\
\hline & -0.01 & 0.99 \\
\hline Block 2 & $(.40)$ & \\
\hline Gender & & \\
\hline & $-1.36^{* *}$ & 0.26 \\
\hline GPA & $(.39)$ & \\
\hline & -0.12 & 0.89 \\
\hline Years after graduation & $(.48)$ & \\
\hline & 0.05 & 1.05 \\
\hline University 2 & $(.05)$ & \\
\hline & 0.74 & 2.09 \\
\hline University 3 & $(.47)$ & \\
\hline & 0.77 & 2.16 \\
\hline Passed PHR & $(.52)$ & \\
\hline & $11.04^{*}$ & 2.84 \\
\hline Constant & $(.46)$ & \\
\hline P<.05*** $p<.019$ & 0.75 & 1.62 \\
\hline
\end{tabular}

${ }^{*} p<.05 ;{ }^{* *} p<.01$.

Hypotheses 2 and 3 concerned the effect of passing the PHR certification exam on Job 1 starting salary and number of promotions for alumni who obtained a job in HR after graduation. Results from the linear regression analyses, reported in Table 3, indicate that passing the PHR exam is not a significant predictor of Job 1 starting salary $(b=-.04, n s)$ or of the number of promotions $(B=-.05, n s)$. Thus, neither of these hypotheses is supported.

Table 3. Linear regression results - determinants of starting salary and promotions

\begin{tabular}{|l|l|l|}
\hline Variable & Starting salary (first job) $\boldsymbol{b}$ & Number of promotions $\boldsymbol{6}$ \\
\hline Gender & $.23^{* *}$ & .03 \\
\hline GPA & $.17^{*}$ & .16 \\
\hline Years after graduation & $-.30^{* *}$ & $.23^{* *}$ \\
\hline University 2 & -.02 & -.04 \\
\hline
\end{tabular}




\begin{tabular}{|l|l|l|}
\hline University 3 & .12 & -.04 \\
\hline Passed PHR & -.04 & -.05 \\
\hline
\end{tabular}

${ }^{*} p<.05 ;{ }^{* *} p<.01$.

\section{Discussion}

Holding a certification demonstrates a general knowledge of and competence in a particular area of professional practice. Currently, while HR students who pass the PHR exam are not technically certified until they complete 2 years of exempt-level experience, according to signaling theory (Spence, 1973), passing the exam demonstrates that they have obtained a standardized level of proficiency in HRM knowledge. The purpose of our study is to examine the impact of voluntary certification in the field of HRM on these new job entrants' early career success. Career success is measured as the accumulation of such external, tangible rewards as employment in their chosen field, higher starting salaries, and expedited promotions.

The most important finding of this study is that passing the PHR exam was significantly related to securing a job in the HRM field upon graduation. This finding suggests that HR majors who are firm in their desire to work in the HR profession benefit by investing the time and money necessary to assist them in passing the PHR before (or just after) graduation. As human capital theory (Wayne et al., 1999) predicts, this investment appears to pay off quickly for those who pass the exam because they will be more than twice as likely to obtain a job in the HRM field upon graduation, all other things being equal. That is, the PHR exam is an effective mechanism that undergraduate HR majors can use to gain entrance to the HRM field. Given the anecdotal evidence of the challenges students face in entering the HR field when they lack HR work experience, this finding has substantial practical significance.

While the aforementioned finding suggests that passing the PHR exam serves the test taker extremely well in terms of gaining entry to the HR field, passing the PHR exam did not account for any statistically significant differences in salary or expedited promotions for those who entered the HRM field. Our findings suggest that those students who are driven by monetary rewards should not view the PHR certification exam as a mechanism for attaining a higher starting salary or more rapid career advancement. One explanation for these findings may be that passing the PHR exam signals a basic level of competence in HR knowledge to get a 'foot in the door' to the HR profession, but employers require exempt-level experience in an applied setting before rewarding new entrants with increased salaries and promotions. It is not surprising that promotions would be based on job performance and work experience, which may not be strongly correlated with PHR certification. Those making the compensation and promotion decisions may expect these new hires to prove themselves on the job before earning additional extrinsic rewards.

\subsection{Practical implications}

Most universities would agree that effectively preparing students for entry into their desired profession is one of their top priorities. One implication of our findings is that external validation of student learning, in this case by successfully passing a voluntary certification exam, provides graduates with an effective mechanism for signaling to employers that they are ready to move into the profession. Ultimately, this validation assists them in entering their chosen field upon graduation from their undergraduate program.

This finding is particularly timely for the HR profession. As mentioned at the beginning of this paper, subsequent to the data collection in this study, the HR Certification Institute recently decided to change its PHR eligibility requirements. As of May 2011, students and recent graduates will be required to have completed 2 years of exempt-level HR experience before they can sit for the PHR exam. Our findings suggest that students/recent graduates may find gaining entrance into the profession more difficult when the new eligibility requirements are enacted. It is possible that they will run into a frustrating scenario of not being able to satisfy the written exam 
component of certification because they lack the necessary exempt-level experience, while at the same time not being able to gain the needed experience because recruiters will be less confident in hiring people right out of school (who lack HR experience) without an external validation of their functional knowledge.

Given our findings, we suggest that thoughtful consideration be given to the possibility of developing an alternate HR job knowledge test, which would be available to and serve as an external validation for students and recent graduates. An alternative validation tool may prove extremely beneficial to at least three groups: HR graduates entering the field, universities preparing these HR majors, and organizations hiring for HR positions. $\mathrm{HR}$ graduates, as noted previously, would have a mechanism for demonstrating their competency. Universities would have a tool to demonstrate to external accrediting bodies that their students are indeed achieving prescribed learning goals. Finally, and most importantly, organizations could be more effective in their hiring of HR positions. The more data that organizations can use to assess the capabilities of potential employees, the more likely they are to make an effective hire the first time around which will save them thousands of dollars in the long run.

\subsection{Strengths, limitations, and directions for future research}

This investigation seeks to address a significant gap in the existing literature regarding the importance of the PHR exam as a facilitator of career success. This study is the first to empirically compare recent college graduates, who passed the PHR exam with those who did not take or did not pass the exam on several objective measures of early career success.

This study does have several limitations. We collected data from alumni of three universities to obtain a sample size that was adequate to conduct the analyses described above. However, sample size remains an issue. With a larger sample, more relationships may have achieved statistical significance and, one would be more confident in the statistical power of the analyses to detect actual effects. The sample population is limited to the Midwest. Consequently, the results of this study may not be generalized to the broader population.

Another limitation is that the study results are based on self reported data. While it is unlikely that organizations would respond to a survey asking for individual salary data, we recognize that actual company data would have been preferred and would have guaranteed greater accuracy for the testing of Hypothesis 2. Furthermore, we asked alumni who graduated up to 10 years ago to recall information (e.g., salary) about their first job out of college. Given the job and life changes that occur over the years, recall of such detailed information can be difficult. Controlling for years since graduation should control for systematic differences in recall due to the passage of time. Nevertheless, future researchers could collect salary information from respondents on a 1-year rolling basis, thereby insuring that it is more accurate (for situations where company data is not accessible).

The current investigation examined a sample of recent graduates and concentrated on the potential benefits of passing the PHR. It may be that passing the PHR will not lead to significant differences in salary and promotions until the professional has met a minimum level of experience in the field and formal certification is achieved. In addition, certification may have a greater impact at the SPHR level. More empirical research on the SPHR and its benefits would also be informative.

Lastly, and most importantly, the field would greatly benefit from empirical research that links HR certification with successful HR job performance. We believe that this is the most promising area for future research. If higher HR job performance is shown to be a direct result of PHR certification, this would not only further validate the PHR exam, but also lead to increased acceptance of certification within the field. Examinations of the relationships between certification and objective performance measures will be critical to a better understanding of how much value the PHR certification exam contributes to the HR profession. 


\section{Conclusion}

In today's highly competitive marketplace, our study does show that a graduate's ability to list success on the PHR certification exam on his/her resume is one promising way to help graduates gain entry into the profession. The HR Certification Institute decision to change upcoming eligibility requirements, however, means that students will no longer be eligible to take the PHR exam before fulfilling the exempt-level experience requirement. Our study suggests that an alternative exam should be created so that students still have an external mechanism by which to demonstrate their HR competence at the time of graduation. As our results show, this type of mechanism may not only be of benefit to students in terms of marketability but also of benefit to recruiters that are trying to identify the best HR talent available for their organization.

\section{Acknowledgements}

The authors wish to thank Sonya Arendt for her work on earlier conference versions of this manuscript and for her assistance on the initial literature review for this manuscript. Her ideas and diligence in the early stages of this project are greatly appreciated.

\section{References}

Aguinis, H., Michaelis, S.E. and Jones, N.M. (2005). Demand for certified human resource professionals in internet-based job announcements. International Journal of Selection and Assessment, 13, 160- 171.

Arthur, M.B., Khapova, S.N. and Wilderom, C.P.M. (2005). Career success in a boundaryless career world. Journal of Organizational Behavior, 26, 177- 202.

Briggs, L.A., Brown, H., Kesten, K. and Heath, J. (2006). Certification: A benchmark for critical care nursing excellence. Critical Care Nurse, 26, 47- 53.

Burns, A.C. and Bush, R.F. (2005). Marketing research: Online research applications. Upper Saddle River, NJ: Pearson Prentice Hall.

Campbell, C. (2004). Clinical engineering certification: Validity and value. Journal of Clinical Engineering, 29, 26- 27.

Cherrington, D.J. and Leonard, B. (1993). HR pioneers' long road to certification. HRMagazine, 38, 63- 75.

Dye, D.M., Reck, M. and McDaniel, M.A. (1993). The validity of job knowledge measure. International Journal of Selection and Assessment, 1, 153- 157.

Eby, L.T., Butts, M. and Lockwood, A. (2003). Predictors of success in the era of the boundaryless career. Journal of Organizational Behavior, 24, 689- 708.

Forrest, E. (2003). Internet marketing intelligence: Research tools, techniques, and resources. Boston, MA: McGraw-Hill-Irwin.

Gattiker, U.E. and Larwood, L. (1988). Predictors for managers' career mobility, success, and satisfaction. Human Relations, 41, 569- 591.

Glister, P. (2000). HR certification's technology gap. Workforce, 79, 72-80.

Hansen, K. (2006). Certifiably empowering: Hot fields in which certification may boost your career Quintessential Careers. Retrieved from http://quintcareers.com/certification/career_certifications.html.

Heslin, P.A. (2005). Conceptualizing and evaluating career success. Journal of Organizational Behavior, 26, 113- 136.

HR Certification Institute. (2008a). One out of two hiring managers prefer HR-certified professionals. Press release.

HR Certification Institute. (2008b). Value of certification summary. Research report.

Hunsinger, D.S. and Smith, M.A. (2008). Factors that influence informations systems undergraduates to purse IT certification. Journal of Information Technology Education, 7, 247- 265.

Losey, M.R. (1993). Committing to lifelong excellence. HRMagazine, 38, 108- 110.

McDaniel, C. and Gates, R. (2005). Marketing research (6th ed..). Hoboken NJ: John Wiley \& Sons Inc.

McFarland, B. (2000). HR students pursue professional certification. HRMagazine, 45, 20. 
Meisinger, S. (2004). Certification is worth the effort ... and then some. HRMagazine, 49, 12.

Miracle, V.A. (2007). Thinking about certification. Dimensions of Critical Care Nursing, 26, 72- 75.

National Association of Colleges and Employers. (2009). Salary Survey, 481, 4-0.

Robert Half International Inc. (2005). 2006 Salary guide Robert Half Finance and Accounting. Retrieved from http://www.roberthalffinance.com/html/downloads/financials2006sg.pdf.

Roberts, J.K. (2002). Certifications grow in value. Computer Reseller News, 1001, 56- 58.

Spence, M. (1973). Job market signaling. Quarterly Journal of Economics, 87, 355- 374.

Sturges, J., Conway, N., Guest, D. and Liefooghe, A. (2005). Managing the career deal: The psychological contract as a framework for understanding career management, organizational commitment and work behavior. Journal of Organizational Behavior, 26, 821-838.

Sunoo, B.P. (1999). Certification enhances HR's credibility. Workforce, 78, 70-80.

Turner, R.H. (1960). The sponsored and contest mobility and the school system. American Sociological Review, 25, 855- 867.

Tyler, K. (1997). Software certifications boost productivity. HRMagazine, 42, 63- 72.

Waldman, D. and Korbar, T. (2004). Student assessment center performance in the prediction of early career success. Academy of Management Learning and Education, 3, 151- 167.

Wayne, S.J., Liden, R.C., Kraimer, M.L. and Graf, I.K. (1999). The role of human capital, motivation, and supervisor sponsorship in predicting career success. Journal of Organizational Behavior, 20, 577- 596.

Weeden, K.A. (2002). Why do some occupations pay more than others? Social closure and earnings inequality in the United States. American Journal of Sociology, 108, 55- 101.

Wiley, C. (1992a). The certified HR professional. HRMagazine, 37, 77-84.

Wiley, C. (1992b). The wave of the future: Certification in human resource management. Human Resource Management Review, 2, 157- 170.

Wiley, C. (1999). A Comparative analysis of certification in human resource management. The International Journal of Human Resource Management, 10, 737- 762. 